\title{
Hyperthermic potentiation of cisplatin by magnetic nanoparticle heaters is correlated with an increase in cell membrane fluidity
}

This article was published in the following Dove Press journal:

International Journal of Nanomedicine

6 March 2013

Number of times this article has been viewed

\section{Merlis P Alvarez-Berríos \\ Amalchi Castillo \\ Janet Mendéz \\ Orlando Soto \\ Carlos Rinaldi \\ Madeline Torres-Lugo}

Department of Chemical Engineering, University of Puerto Rico, Mayagüez, Puerto Rico
Correspondence: Madeline Torres-Lugo Department of Chemical Engineering, University of Puerto Rico, Mayaguez Campus, PO Box 9000 , Mayaguez 0068I, Puerto Rico $\mathrm{Tel}+\mathrm{I} 7878324040$ ext 2585 Fax +l 7878343655

Email madeline@ece.uprm.edu
Abstract: Magnetic fluid hyperthermia as a cancer treatment method is an attractive alternative to other forms of hyperthermia. It is based on the heat released by magnetic nanoparticles subjected to an alternating magnetic field. Recent studies have shown that magnetic fluid hyperthermia-treated cells respond significantly better to chemotherapeutic treatment compared with cells treated with hot water hyperthermia under the same temperature conditions. We hypothesized that this synergistic effect is due to an additional stress on the cellular membrane, independent of the thermal heat dose effect that is induced by nanoparticles exposed to an alternating magnetic field. This would result in an increase in Cis-diammine-dichloroplatinum (II) (cDDP, cisplatin) uptake via passive transport. To test this hypothesis, we exposed cDDPtreated cells to extracellular copper in order to hinder the human cell copper transporter (hCTR1)-mediated active transport of cDDP. This, in turn, can increase the passive transport of the drug through the cell membrane. Our results did not show statistically significant differences in surviving fractions for cells treated concomitantly with magnetic fluid hyperthermia and cDDP, in the presence or absence of copper. Nonetheless, significant copper-dependent variations in cell survival were observed for samples treated with combined cDDP and hot water hyperthermia. These results correlated with platinum uptake studies, which showed that cells treated with magnetic fluid hyperthermia had higher platinum uptake than cells treated with hot water hyperthermia. Changes in membrane fluidity were tested through fluorescence anisotropy measurements using trimethylamine-diphenylhexatriene. Additional uptake studies were conducted with acridine orange and measured by flow cytometry. These studies indicated that magnetic fluid hyperthermia significantly increases cell membrane fluidity relative to hot water hyperthermia and untreated cells, and hence this could be a factor contributing to the increase of cDDP uptake in magnetic fluid hyperthermia-treated cells. Overall, our data provide convincing evidence that cell membrane permeability induced by magnetic fluid hyperthermia is significantly greater than that induced by hot water hyperthermia under similar temperature conditions, and is at least one of the mechanisms responsible for potentiation of cDDP by magnetic fluid hyperthermia in Caco-2 cells.

Keywords: magnetic nanoparticles, synergistic effect, hot water hyperthermia, surviving fraction, viability ratio

\section{Introduction}

Hyperthermic potentiation, defined as the improved effect obtained through a combination of heat and chemo/radiotherapy, has shown promising results in the treatment of cancer. ${ }^{1,2}$ Over the years, an increasing number of reports regarding use of hyperthermia in conjunction with antineoplastic modalities have provided substantial evidence of its enhanced efficacy. ${ }^{3}$ Nonetheless, current clinical applications using 
local, regional, and whole body hyperthermia have a number of disadvantages, including limitations in achievable treatment depth, complications due to patient surface irregularities (eg, head, arms), and overheating of adjacent normal tissue. Consequently, novel hyperthermic treatment options are of significant interest. ${ }^{4}$

The mechanisms involved in the hyperthermic potentiation of antineoplastic modalities are diverse. However, increased membrane fluidity has been proposed to be a reasonable cause of this potentiation. ${ }^{5-7}$ Cis-diamminedichloroplatinum (II) (cDDP, cisplatin) is a well characterized chemotherapeutic agent that has shown promising results when combined with hyperthermia, but its mechanisms of potentiation remain largely unknown. ${ }^{8,9}$ Uptake of cDDP by the cell appears to be mediated by two distinct mechanisms, ie, active transport via copper transporter receptors and passive diffusion through the cellular membrane. ${ }^{10}$ Currently, it is believed that active transport is the dominant mechanism of cDDP uptake. ${ }^{11}$ Studies have implicated regulators of copper homeostasis, including the primary human cell copper transporter (hCTR1), as being responsible for modulating the cytotoxic activity of cisplatin and other platinum-based drugs. ${ }^{12}$ hCTR1 is rich in histidine and methionine residues, for which both copper and cisplatin have been shown to have high affinity and bind competitively. ${ }^{13}$

Numerous studies have highlighted the cytoprotective effects of copper in cDDP-exposed yeast and mammalian cells, emphasizing its dependence on hCTR receptors. ${ }^{14-17}$ Although some groups report distinct molecular behaviors of the different members of the hCTR family, which appear to be cell-dependent, all reports agree that copper, due to its affinity with the hCTR receptor, affects receptormediated entry of cDDP negatively, resulting in improved cytotoxicity. ${ }^{9,18-23}$

Although copper receptors have a critical role in the uptake of cisplatin, one of the first studies that focused on the mechanisms of thermal enhancement of cDDP reported an increase in cell membrane fluidity, which in turn augmented the uptake of cDDP. ${ }^{17,24,25}$ Therefore, the synergism of cDDP and hyperthermic treatment can potentially be explained in the context of membrane fluidity. However, the means by which hyperthermia is induced can also have additional effects on cells that must be taken into account.

The range of technologies by which hyperthermia is induced has expanded greatly in recent years. The use of magnetic nanoparticles to induce hyperthermia, so-called magnetic fluid hyperthermia, has shown promising in vitro and in vivo results. ${ }^{26,27}$ Recent studies have also explored magnetic nanoparticles as a means of enhancing chemotherapeutic efficacy. ${ }^{28}$ When inducing hyperthermia using magnetic nanoparticles, the physical mechanisms inherent in the dissipation of heat by these particles may exert an additional stress that goes beyond thermal effects and which results in enhanced potentiation of chemotherapeutics. Previously, we reported that magnetic fluid hyperthermia resulted in enhanced cytotoxicity when compared with hot water hyperthermia alone in two separate cell lines, and subsequently we showed that magnetic fluid hyperthermia resulted in significantly enhanced cytotoxicity when combined with cDDP, as compared with hyperthermia using a water bath. ${ }^{29,30}$

In this study, we endeavored to characterize some of the differences in hyperthermic potentiation of cDDP using hot water hyperthermia and magnetic fluid hyperthermia. We hypothesized that magnetic fluid hyperthermia induces membrane fluidization by an additional thermal or physical stress on the cellular membrane, and that this in turn is responsible for increased intracellular accumulation of cDDP when compared with the effect of hot water hyperthermia. To test this hypothesis, we made direct and indirect measurements of cell membrane fluidity. First, the cell response to cDDP was measured using viability and clonogenic assays and platinum uptake measurements. To take advantage of the competitive binding effect of cisplatin and copper, we exposed a Caco-2 cell line to extracellular copper, thus hindering hCTR1-active receptor transport and permitting preferential passive diffusion via the cell membrane. ${ }^{10,31}$ In addition, fluorescence anisotropy using trimethylamine-diphenylhexatriene (TMADPH) and acridine orange (Life Technologies, Carlsbad, CA, USA) diffusion measurements were done to quantify the extent of membrane fluidity induced by magnetic fluid hyperthermia and hot water hyperthermia. Our results show that cell membrane permeability induced by magnetic fluid hyperthermia is higher than that induced by hot water hyperthermia under similar temperature conditions. This increase in membrane fluidity induced by magnetic fluid hyperthermia is at least one of the mechanisms responsible for magnetic fluid hyperthermia potentiation of cDDP in Caco-2 cells.

\section{Materials and methods Caco- 2 cell culture}

Caco-2 cells were obtained from the American Type Culture Collection (ATCC) (Manassas, VA, USA). Cells were cultured in $75 \mathrm{~cm}^{2}$ flasks (Costar, Corning, NY, USA) using Dulbecco's modified Eagle's medium (Sigma-Aldrich, St Louis, MO, USA) containing 10\% fetal bovine serum 
(Life Technologies), 1\% nonessential amino acids (Life Technologies), $100 \mathrm{U} / \mathrm{mL}$ penicillin (Sigma-Aldrich), and $100 \mu \mathrm{g} / \mathrm{mL}$ streptomycin (Sigma-Aldrich), supplemented with $2 \mathrm{mM}$ L-glutamine and $24 \mathrm{mM}$ sodium bicarbonate. Cells were maintained at $37^{\circ} \mathrm{C}, 95 \%$ relative humidity, and $5 \% \mathrm{CO}_{2}$. Cell passages were performed weekly, while testing for mycoplasma contamination monthly.

\section{Nanoparticle suspension}

The nanoparticles used in this study are from the same batch used in a previous study by Rodriguez-Luccioni et al. ${ }^{29}$ For expedience, we summarize their preparation and characterization. Briefly, the iron oxide (IO) nanoparticles were synthesized by the coprecipitation method. An aqueous solution of ferric chloride and ferrous chloride with ammonium hydroxide at $80^{\circ} \mathrm{C}$ was mixed and stirred for 1 hour at $\mathrm{pH} 8.0$ with bubbling nitrogen. After cooling to room temperature, the solution was centrifuged at $1800 \mathrm{rpm}$ for 5 minutes to precipitate the nanoparticles. Nanoparticles were peptized with $0.5 \mathrm{M} \mathrm{HNO}_{3}$, centrifuged for 15 minutes at $3500 \mathrm{rpm}$, and resuspended in water. Afterwards, the IO nanoparticles were functionalized with carboxymethyl dextran and characterized. The content of IO in the nanoparticles was determined using a thermogravimetric analyzer (TA-2950; TA Instruments, Newcastle, DE, USA). The hydrodynamic diameter was determined by dynamic light scattering using a particle size analyzer (BI-90 Plus; Brookhaven Instrument Corp, Holtsville, NY, USA). The specific absorption rate was measured by placing a suspension of nanoparticles at a concentration of $0.6 \mathrm{mg} \mathrm{IO/}$ $\mathrm{mL}$ in an induction heater instrument (RDO Enterprises Inc, Washington, NJ, USA) and applying a magnetic field of 20 $\mathrm{kA} / \mathrm{m}$ and $238 \mathrm{kHz}^{29}$

The nanoparticles were autoclaved for 60 minutes at a temperature of $121^{\circ} \mathrm{C}$ and $15 \mathrm{psi}$. The autoclaved particles were characterized to verify particle integrity, dispersion, and stability. Once characterized, the particles were suspended in Dulbecco's modified Eagle's medium prior to in vitro testing. The final particle concentration was $2 \mathrm{mg}$ particles per $\mathrm{mL}$ (0.6 mg IO/mL).

\section{$\mathrm{IC}_{50}$ determination}

$\mathrm{IC}_{50}$ values were determined using Cell Titer Blue ${ }^{\mathrm{TM}}$ cell viability (Promega, Madison, WI, USA) and clonogenic assays. The cells were seeded in 96-well plates (Thermo Fisher Waltham, MA, USA) and allowed to adhere for 48 hours in Dulbecco's modified Eagle's medium. Adherent cells were exposed to increasing concentrations of $\operatorname{cDDP}(0.3-200 \mu \mathrm{M}$; Sigma-Aldrich) with and without $5 \mu \mathrm{M} \mathrm{Cu}^{2+}$ (Sigma-Aldrich) for 2.5 hours. Cells were then washed twice with Hank's balanced salt solution (Sigma-Aldrich) buffer and allowed to recover in Dulbecco's modified Eagle's medium for one week at $37^{\circ}$ and $5 \% \mathrm{CO}_{2}$. After this recovery period, the Dulbecco's modified Eagle's medium was discarded and the cells were washed twice with Hank's balanced salt solution, stained with CellTiter Blue, and analyzed fluorometrically (Spectra MAX Gemini EM; Molecular Devices, Sunnyvale, CA, USA). For clonogenic assay, the cells $\left(5 \times 10^{5}\right.$ cells suspended in $2.5 \mathrm{~mL}$ of complete Dulbecco's modified Eagle's medium) were exposed to increasing concentrations of cDDP (0.3-200 $\mu \mathrm{M})$ with and without $5 \mu \mathrm{M} \mathrm{Cu}{ }^{2+}$ for 2.5 hours. Subsequently, the cells were washed by centrifugation and counted manually using Trypan blue (Sigma-Aldrich).

Different cell dilutions (2000-7000 cells) were seeded in six-well plates (Thermo Fisher Scientific) and allowed to form colonies for 10 days. After this time, the colonies were fixed, stained with crystal violet, and counted in the manner reported by Franken et al. ${ }^{32}$

\section{Synergism studies}

Hot water hyperthermia

Approximately $5 \times 10^{5}$ cells suspended in $2.5 \mathrm{~mL}$ of complete Dulbecco's modified Eagle's medium were transferred to $10 \mathrm{~mL}$ glass tubes and placed in a temperature-regulated water bath. Further temperature assessment was performed using a thermometer at 15-minute intervals. Control tubes were half-sealed to allow $\mathrm{CO}_{2}$ exchange and remained in the incubator at $37^{\circ} \mathrm{C}$ for a period of 2.5 hours. Caco- 2 cell samples were either treated or not treated with cisplatin $(5 \mu \mathrm{M}), \mathrm{Cu}^{2+}$ (5 $\mu \mathrm{M})$, or both, and heated to $41^{\circ} \mathrm{C}$ for 30 minutes. We decided to use mild hyperthermia $\left(41^{\circ} \mathrm{C}\right)$ in order to distinguish better the synergistic effect between hyperthermia and cDDP. Application of higher temperatures would lead to significant decreases in cell viability, precluding differentiation of cell response to the various treatments. After treatment, the cells were incubated for a further 2 hours at $37^{\circ} \mathrm{C}$. The cells were subsequently centrifuged for 10 minutes, the treatment medium was discarded, and the cells were resuspended in $2.5 \mathrm{~mL}$ of drug-free medium. The cells were seeded in a $25 \mathrm{~cm}^{2}$ flask (Costar) for 48 hours at $37^{\circ} \mathrm{C}$ and $5 \% \mathrm{CO}_{2}$. The cells were then trypsinized and cell viability was measured using Trypan blue. The surviving fraction was assessed by clonogenic assay as explained above.

\section{Magnetic fluid hyperthermia}

Approximately $5 \times 10^{5}$ cells (in $2.5 \mathrm{~mL}$ final Dulbecco's modified Eagle's medium suspension) were transferred to $10 \mathrm{~mL}$ 
glass tubes and treated with cDDP $(5 \mu \mathrm{M})$, copper $(5 \mu \mathrm{M})$, neither or both, concomitantly with a concentration of $2 \mathrm{mg} /$ $\mathrm{mL}$ of autoclaved IO carboxymethyl dextran nanoparticles. The tubes were then placed in the coil of the heat induction equipment and exposed to an alternating magnetic field. The environment surrounding the sample was kept at $37^{\circ} \mathrm{C}$ using an incubator enclosure. The sample temperature increased to $41^{\circ} \mathrm{C}$ due to energy dissipation by the nanoparticles and was held at that temperature for 30 minutes. A frequency of $237 \mathrm{kHz}$ and a magnetic field of $20 \mathrm{kA} / \mathrm{m}$ were applied during the treatment period. After treatment, the cells were incubated for a further 2 hours at $37^{\circ} \mathrm{C}$. The cells were then spun down for 10 minutes and the treatment medium was discarded. The cells were resuspended in $2.5 \mathrm{~mL}$ of Dulbecco's modified Eagle's medium. The viability fraction and surviving fraction were assessed as previously described.

\section{cDDP uptake studies}

Approximately $10 \times 10^{6}$ cells were exposed to either cDDP $(5 \mu \mathrm{M})$, copper $(5 \mu \mathrm{M})$ or both, and treated for 30 minutes with magnetic fluid hyperthermia or hot water hyperthermia at $41^{\circ} \mathrm{C}$. The samples were subsequently placed in the incubator at $37^{\circ} \mathrm{C}$ for a period of 2 hours. At the end of the treatment period, the cells were removed from the test tubes and centrifuged at $800 \mathrm{~g}$ for 10 minutes in order to remove the drug. The pellets were washed three times with phosphatebuffered saline at $4^{\circ} \mathrm{C}$. After the final wash, the supernatant was aspirated and the pellet was frozen at $-20^{\circ} \mathrm{C}$, while awaiting uptake assay. The pelleted cells were resuspended in $200 \mu \mathrm{L}$ of ultrapure water to obtain a homogeneous cell suspension. The suspended cells were transferred into glass tubes containing $70 \% \mathrm{HNO}_{3}$ and then mineralized until completely dried at $80^{\circ} \mathrm{C}$. The mineralized sample was dissolved in $2 \mathrm{~mL}$ of $2 \% \mathrm{HNO}_{3}$ containing $50 \mu \mathrm{g} / \mathrm{L}$ of indium (used as the internal standard). The samples were further disrupted by means of sonication for 10 minutes, resulting in a clear solution. ${ }^{33}$ Sample analysis for platinum content was made using an inductively coupled plasma-mass spectrometer (X5 Series; Thermo Optek, Cinisello Balsamo, Italy). Concentration values were corrected to the indium signal. ${ }^{33}$

\section{Membrane fluidization studies}

Membrane fluidity was determined by measuring fluorescence anisotropy using TMA-DPH. After the cell samples had undergone treatment, TMA-DPH was added to a final concentration of $5 \mu \mathrm{M}$ and the samples were allowed to incubate for 5 minutes prior to measurements. Fluorescence intensity measurements parallel or perpendicular to the direction of the excitation beam were read using a fluorescence spectrometer (USB4000; Ocean Optics, Henderson, NV, USA) with an external excitation source (100 $\mathrm{mW}$, excitation wavelength 405 nm, emission 430 nm; Wicked Lasers, Hong Kong, People's Republic of China). Fluorescence anisotropy values are inversely proportional to cell membrane fluidity and are quantified according to:

$$
\mathrm{r}=\frac{\mathrm{I}_{\mathrm{vv}}-\mathrm{I}_{\mathrm{vh}}}{\mathrm{I}_{\mathrm{vv}}+2 \mathrm{I}_{\mathrm{vh}}}
$$

where $\mathrm{I}_{\mathrm{vv}}$ is the fluorescence intensity emitted parallel to the direction of excitation light, and $\mathrm{I}_{\mathrm{vh}}$ is fluorescence intensity emitted perpendicular to excitation light. ${ }^{34}$

\section{Flow cytometer}

Cells $\left(5 \times 10^{5}\right)$ were stained with acridine orange immediately after hyperthermic treatment to a concentration of $1 \mu \mathrm{g} / \mathrm{mL}$ for a period of 5 minutes, then washed and resuspended in phosphate-buffered saline. Green (500-550 nm, FL1 channel) fluorescence, which was illuminated with blue ( $488 \mathrm{~nm})$ light excitation, was measured using a flow cytometer (Accuri C6; Becton Dickinson, Ann Arbor, MI, USA).

\section{Confocal microscopy}

Cells stained with acridine orange were washed and resuspended in phosphate-buffered saline. Next, $20 \mu \mathrm{L}$ of the cell suspension was aliquoted onto a microscope slide and immediately overlayed with a cover slip. Pictures were obtained with a spinning disk (Intelligent Imaging Innovations Inc, Denver, CO, USA) confocal microscope (Olympus IX81; Olympus America, Center Valley, PA, USA) equipped with a Xenon Fl source for visualization. Images were captured using a $60 \times$ oil immersion objective and Rolera EM-C2 camera (Quantitative Imaging Corporation, Cary, NC, USA). Experiments were repeated twice, and two images were obtained for each sample analyzed. All pictures were taken with an identical exposure time.

\section{Statistical analysis}

The sample size was $n=3$ for all experiments except for confocal imaging $(\mathrm{n}=2)$ and the control group in platinum uptake analysis $(n=4)$. Statistical analyses were conducted using the Student's $t$-test (two-tailed distribution, two-sample with unequal variances). Differences were considered significant at $P<0.05$. The standard error and surviving fraction for clonogenic assay studies were determined using the approach established by Gupta et al. ${ }^{35}$ 


\section{Results}

\section{Nanoparticle characterization}

The nanoparticles used in this study were the same batch used by Rodriguez-Luccioni et al. ${ }^{29}$ In that study, the hydrodynamic diameter of the IO nanoparticles was determined to be $72 \pm 4 \mathrm{~nm}$ by dynamic light scattering. The inorganic core content was found to be $27 \%$ by weight, as determined by thermogravimetric analysis. A specific absorption rate value of $245 \mathrm{~W} / \mathrm{g}$ was determined at a magnetic field amplitude of 20 $\mathrm{kA} / \mathrm{m}$ and a frequency of $238 \mathrm{kHz}$. Considering that specific absorption rate values generally depend on the magnetic field amplitude and frequency, nanoparticle structure (size and shape), and magnetic properties, the specific absorption rate value obtained for nanoparticles used in this study is consistent with data reported in the literature. ${ }^{26,27}$ For example, IO nanoparticles exposed to a magnetic field amplitude of $24.5 \mathrm{kA} / \mathrm{m}$ and frequency of $400 \mathrm{kHz}$ had a specific absorption rate value of $447 \mathrm{~W} / \mathrm{g} .{ }^{26,36}$ On the other hand, Dennis et al synthesized and studied two different batches of IO nanoparticles coated with dextran. When they were exposed to a magnetic field amplitude of $85.9 \mathrm{kA} / \mathrm{m}$ and a frequency of $150 \mathrm{kHz}$, nanoparticles with lower saturation magnetization had a specific absorption rate value of $209 \mathrm{~W} / \mathrm{g}$, whereas nanoparticles with higher saturation magnetization had a specific absorption rate value of $537 \mathrm{~W} / \mathrm{g}$. 37,38

\section{Effect of extracellular copper on cDDP-induced cell death}

hCTR1-mediated uptake of cDDP into cells has been extensively documented. ${ }^{9-14,19-24}$ It is widely accepted as the primary mechanism of influx of this platinum-based

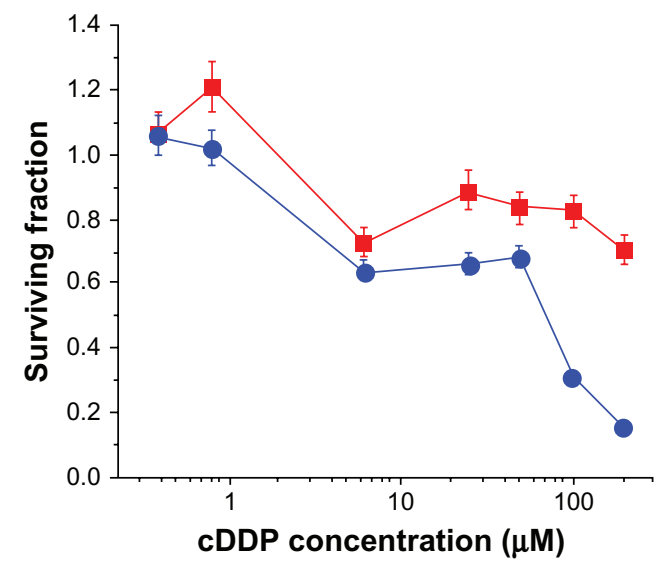

drug in cells. ${ }^{10,11}$ To assess the effect of extracellular copper on this form of drug transport, the surviving fraction and viability ratio of Caco- 2 cells was studied by exposing cells to a mixture of $5 \mu \mathrm{M}$ copper and increasing concentrations of cDDP for 2.5 hours. The concentration of copper was chosen based on its reported binding constant $\left(\mathrm{K}_{\mathrm{m}}\right)$ value. Because $\mathrm{K}_{\mathrm{m}}$ is defined as the copper concentration when the rate of transport through the hCTR1receptor is half of its maximum value, we chose a copper concentration above the $\mathrm{K}_{\mathrm{m}}$ in order to hinder the hCTR 1 receptor. ${ }^{39}$ The surviving fraction of samples began to deviate significantly at cDDP concentrations above $5 \mu \mathrm{M}$, after which the fraction of surviving cells treated without copper dropped dramatically (Figure 1). On the other hand, we observed statistically significant differences in the viability ratio of cells treated with copper at concentrations of cDDP above $40 \mu \mathrm{M}$ (Figure 1). The $\mathrm{IC}_{50}$ value of cDDP in the absence of copper was approximately $80 \mu \mathrm{M}$ for both experimental methods. In the presence of copper, this value increased by approximately $30 \%$. Mild hyperthermia is known to significantly enhance cDDP potentiation, leading to a significant increase in cell death. Consequently, we chose a lower drug concentration of $5 \mu \mathrm{M}$ for subsequent experiments.

Because the magnetic fluid hyperthermia setup requires use of IO carboxymethyl dextran nanoparticles to induce heat, the cells were treated with the required concentration of these nanoparticles $(0.6 \mathrm{mg} \mathrm{IO} / \mathrm{mL})$ in order to evaluate nanoparticle-induced cytotoxicity. Previous work by our group has shown that this concentration of nanoparticles used during magnetic fluid hyperthermia treatment does not induce cell cytotoxicity on its own. ${ }^{29}$

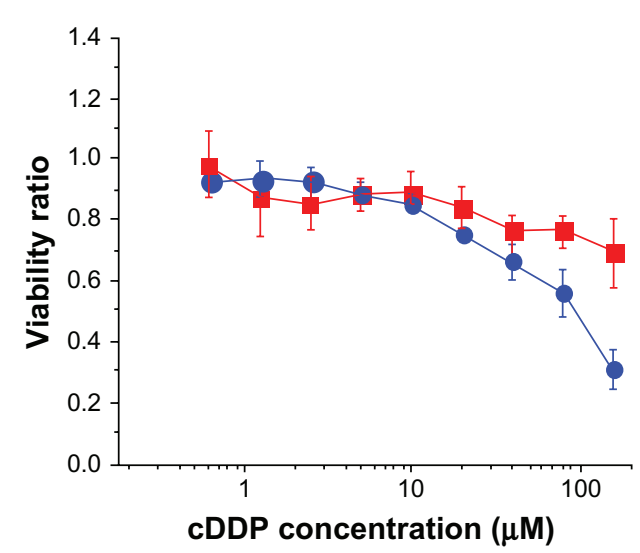

Figure I Surviving fraction and viability ratio of Caco-2 cells as a function of concentration of cDDP for an exposure period of 2.5 hours with copper (squares) and without copper (circles).

Note: Error bars represent the standard error of the mean of three independent experiments.

Abbreviation: cDDP, Cis-diammine-dichloroplatinum (II). 


\section{Effect of copper on cDDP-induced cell death after hyperthermic treatment}

In an initial attempt to explain the differences in enhanced cytotoxicity between both forms of hyperthermic treatment, Caco- 2 cells were treated for 30 minutes at $37^{\circ} \mathrm{C}$ or at $41^{\circ} \mathrm{C}$ using either hot water hyperthermia or magnetic fluid hyperthermia in combination with cDDP or cDDP + copper. After heat treatment, the cells were further exposed to cDDP or cDDP + copper for an additional 2 hours. This treatment sequence was chosen because an independent study had concluded that cDDP potentiation was most effective when the drug and hyperthermic treatment were applied simultaneously, followed by 2 hours of exposure to the drug at $37^{\circ} \mathrm{C} .{ }^{29}$ Cell viability and clonogenicity were quantified. The cytotoxic effects of hot water hyperthermia and magnetic fluid hyperthermia were evident using both assays (Figure 2). Interestingly, the surviving fraction determined using a clonogenic assay was consistently higher than viability ratio determined using trypan blue exclusion test, except for the cells treated with a combination of magnetic fluid hyperthermia and cDDP, with and without copper. The combination of magnetic fluid hyperthermia and cDDP proved to be most effective in reducing Caco-2 viability and clonogenicity, resulting in a statistically significant difference in viability ratio and surviving fractions relative to untreated cells and those treated with hot water hyperthermia (Figure 2, cDDP). In a similar manner,

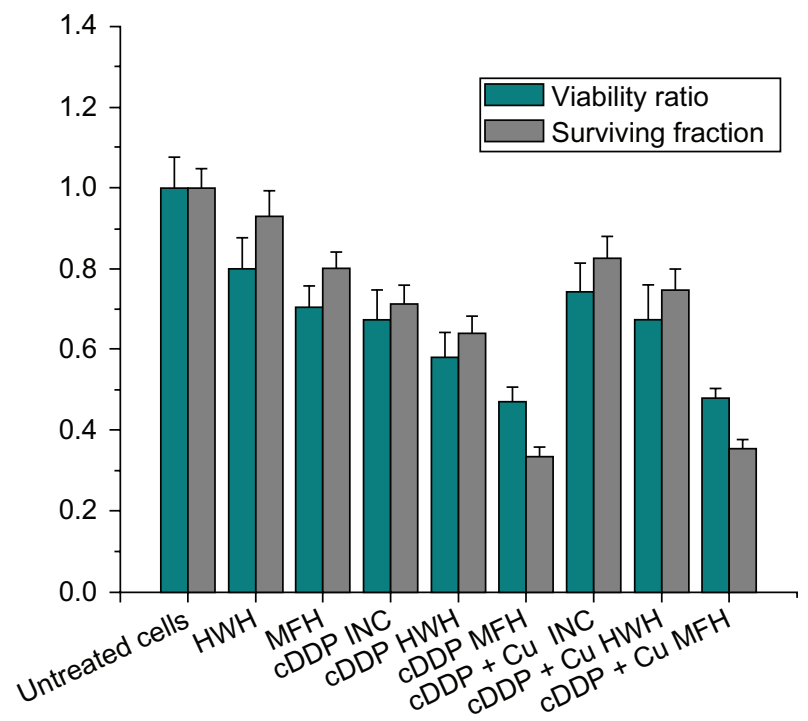

Figure 2 Surviving fraction and viability ratio of Caco-2 cells treated with $5 \mu \mathrm{M}$ cDDP with and without copper for 2.5 hours at $37^{\circ} \mathrm{C}$, and with hot water hyperthermia or magnetic fluid hyperthermia, both at $41^{\circ} \mathrm{C}$.

Notes: Untreated cells, cells maintained in the incubator; cDDP, cells with cisplatin; cDDP $+\mathrm{Cu}$, cells with cisplatin and copper. Error bars represent the standard error of the mean of three independent experiments.

Abbreviation: cDDP, Cis-diammine-dichloroplatinum (II); $\mathrm{HWH}$, hot water hyperthermia; INC, incubator; MFH, magnetic fluid hyperthermia; CU, copper. magnetic fluid hyperthermia was most effective in treating cells concomitantly with cDDP and copper (Figure 2, cDDP + copper). The presence of extracellular copper resulted in a statistically significant difference in the surviving fraction for cells treated with hot water hyperthermia. In contrast, copper appeared to have little or no effect on Caco-2 cell survival in the context of magnetic fluid hyperthermia (Figure 2, cDDP versus cDDP + copper).

\section{Accumulation of cDDP in vitro}

The uptake of platinum in the context of hyperthermia, in the presence and absence of copper, was measured as a means to elucidate the mechanism of cell death induced by hyperthermia and cDDP (Figure 3). Immediately after treatment, the cells were washed three times with cold phosphate-buffered saline by centrifugation, then pelleted and frozen until the samples were ready to be quantified. The use of magnetic fluid hyperthermia and hot water hyperthermia in the presence of cDDP increased platinum uptake significantly when compared with control cells (cells with cDDP in the incubator versus cells with cDDP treated with hot water hyperthermia and those treated with cDDP and magnetic fluid hyperthermia). Furthermore, platinum uptake in cells treated with magnetic fluid hyperthermia was significantly greater than that in cells treated with hot water hyperthermia (cDDP hot water hyperthermia versus cDDP with magnetic fluid hyperthermia). Whereas the presence of extracellular copper served a protective role in our control cells, this was not evident in cells treated with cDDP

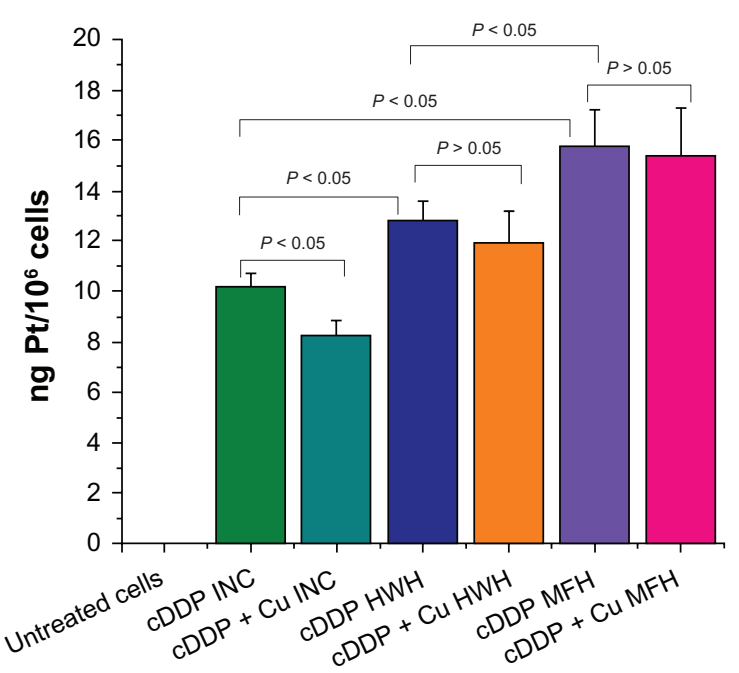

Figure 3 Platinum uptake in Caco-2 cells treated with different thermal modalities in conjunction with copper and cDDP. Values represent the mean \pm SE from $n=3$ for experimental samples and $n=4$ for controls.

Abbreviation: cDDP, Cis-diammine-dichloroplatinum (II); $\mathrm{HWH}$, hot water hyperthermia; INC, incubator; MFH, magnetic fluid hyperthermia; CU, copper. 
in combination with either magnetic fluid hyperthermia or hot water hyperthermia. However, the surviving fraction of cells treated with magnetic fluid hyperthermia and cDDP in the presence of copper was lower than that of cells treated with hot water hyperthermia under the same conditions (Figure 2). Taken together, these results show that magnetic fluid hyperthermia promotes higher cDDP uptake than hot water hyperthermia at the same temperature of $41^{\circ} \mathrm{C}$. Furthermore, no statistically significant differences in uptake of platinum by hyperthermia-treated cells in the presence of extracellular copper were observed, which suggests that both mild heat treatments are able to increase cell membrane fluidity, such that the protective role of copper is no longer apparent under these conditions. In light of these results, we hypothesized that differences in membrane fluidity induced by both forms of hyperthermic treatment could explain the disparities in platinum uptake, and thereby surviving fraction and viability ratio, among the conditions evaluated. In order to test this hypothesis we conducted fluorescence polarization studies using a membrane-bound TMA-DPH probe.

\section{Increased membrane fluidity in cells treated with magnetic fluid hyperthermia}

TMA-DPH is a cationic derivative of the classic fluorescence polarization probe $\mathrm{DPH}$, and has significant specificity for the cell plasma membrane, by anchoring its charged trimethylammonium group at the polar heads of the phospholipid bilayers and the apolar DPH moiety placed between the fatty acid chains. ${ }^{34}$ TMA-DPH has been used to label the outer leaflet of lipid bilayers in order to follow changes in membrane arrangements by fluorescence anisotropy measurements. These measurements have been shown to correlate with the rotational capability of the probe. ${ }^{40}$

Previous studies have shown that the heat shock response of cells involves an increase in cell membrane fluidity. ${ }^{5-7} \mathrm{We}$ hypothesized that cells that have undergone a mild treatment of hyperthermia $\left(41^{\circ} \mathrm{C}\right.$ and 30 minutes) using magnetic nanoparticles would suffer an additional mechanical stress on their cell membrane, induced by the presence of rotating and/or vibrating nanoparticles in solution, resulting in a higher membrane fluidity than those cells treated with hot water hyperthermia under the same temperature and for the same duration. Consequently, differences in fluorescence anisotropy induced by TMA-DPH would be observed.

Our results showed significant differences in membrane arrangements for both hyperthermic conditions relative to the control, as seen by a decrease in their fluorescence anisotropy reading, with magnetic fluid hyperthermia-treated cells showing significantly greater membrane fluidity than hot water hyperthermia-treated cells (Figure 4). This result suggests that magnetic fluid hyperthermia can induce an additional stress on the cellular membrane, either absent or not as significant in hot water hyperthermia-treated cells, that promotes higher membrane fluidity and which may be responsible for differences in cDDP uptake (Figure 3). In order to determine whether or not the concentration of cDDP used in this study induces membrane fluidity, we quantified changes in anisotropy for Caco-2 cells exposed to cDDP $5 \mu \mathrm{M}$ at $37^{\circ} \mathrm{C}$ for 30 minutes, followed by TMA-DPH labeling. As shown in Figure 4 (red), cDDP-treated cells did not show any significant increase in membrane fluidity compared with the control.

\section{Enhanced passive transport of acridine orange in magnetic fluid hyperthermia-treated cells}

An alternative indirect approach was used to evaluate changes in membrane fluidity of treated cells relative to untreated cells, by measuring the fluorescence intensity of cells exposed to acridine orange (Figure 5). Green fluorescence intensity measurements (as measured using a flow cytometer) were significantly higher in cells treated with mild hyperthermia relative to untreated cells (Figure 5).

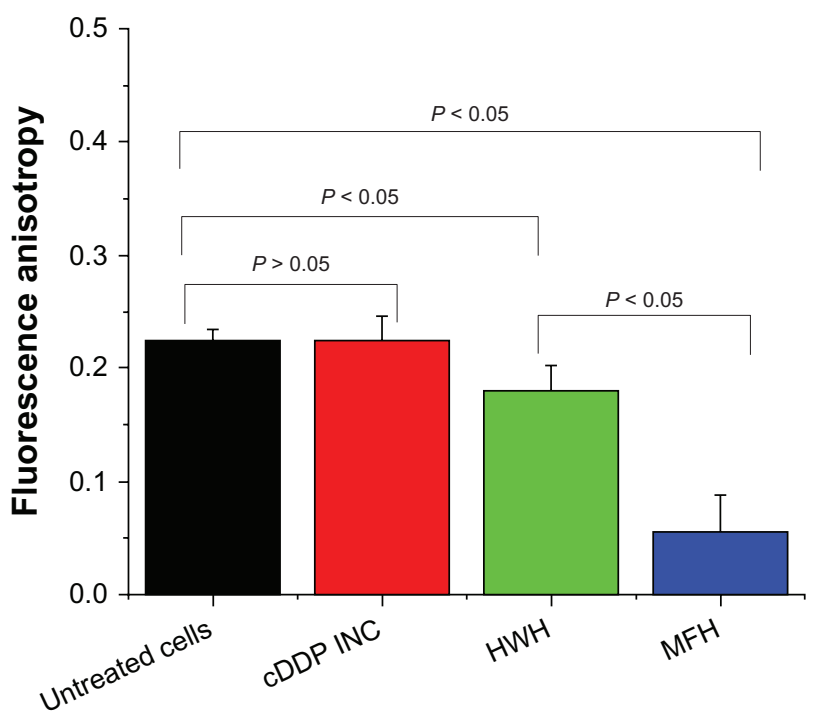

Figure 4 Fluorescence anisotropy changes in cells treated with mild hyperthermia $\left(41^{\circ} \mathrm{C}\right)$ as detected by TMA-DPH.

Notes: Caco-2 cells suspended in phosphate-buffered saline were treated at $41^{\circ} \mathrm{C}$ for 30 minutes, or left at $37^{\circ} \mathrm{C}$, and labeled with TMA-DPH. The fluorescence anisotropy measurements were made at $430 \mathrm{~nm}$. Data correspond to the mean \pm SE for $n=3$.

Abbreviations: TMA-DPH, trimethylamine-diphenylhexatriene; SE, standard error of the mean; INC, incubator; HWH, hot water hyperthermia; MFH, magnetic fluid hyperthermia; cDDP, cis-diammine-dichloroplatinum (II). 


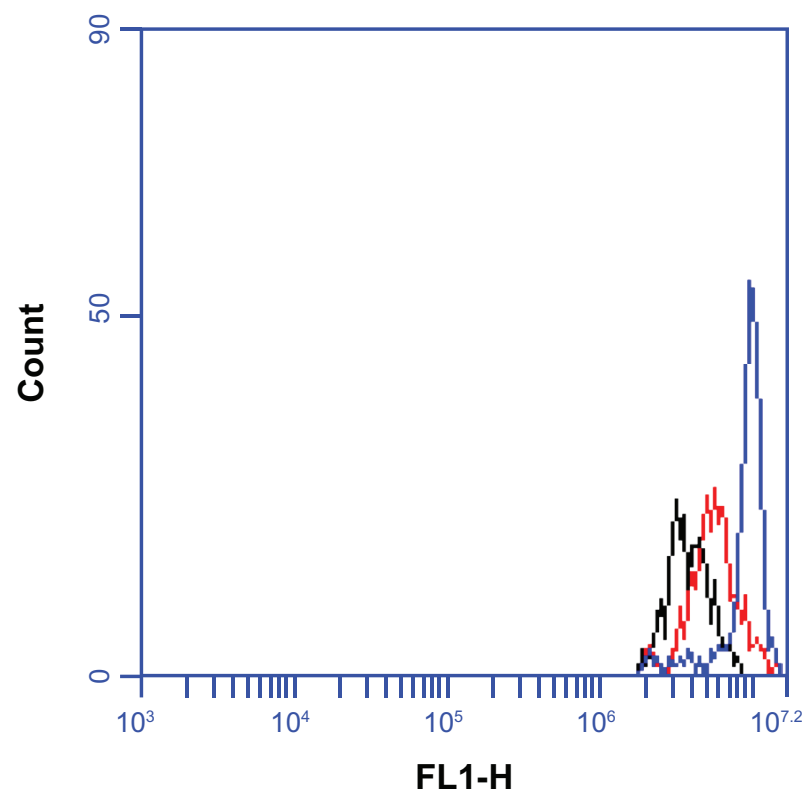

Figure 5 Effect of mild hyperthermia on the fluorescence intensity (as measured by FLI channel) in acridine orange-stained cells (blue, magnetic fluid hyperthermia; red, hot water hyperthermia), relative to untreated cells (black).

Note: Three independent experiments were done.

Furthermore, the green fluorescence intensity of cells treated with magnetic fluid hyperthermia was significantly higher than that of cells treated with hot water hyperthermia. As shown in Table 1, the fold increases in fluorescence intensity observed between magnetic fluid hyperthermia and hot water hyperthermia were statistically different (Table 1). Finally, qualitative imaging of samples (Figure 6) showed incorporation of acridine orange. In agreement with flow cytometry measurements, an increase in green fluorescence is more apparent in cells treated with mild hyperthermia, with magnetic fluid hyperthermia-treated cells showing the most significant incorporation of the weak base. These results suggest that the rate of passive diffusion of acridine orange had greater enhancement in magnetic fluid hyperthermia-treated cells, presumably due to an increase in cell membrane fluidity.

Table I Fold increase in fluorescence intensity of cells treated with hot water hyperthermia and magnetic fluid hyperthermia relative to untreated cells

\begin{tabular}{lll}
\hline & FLI intensity & \\
\cline { 2 - 3 } & HWH-treated cells & MFH-treated cells \\
\hline Mean & $1.32^{*}$ & $1.87^{* *}$ \\
SD & 0.08 & 0.05 \\
SE & 0.05 & 0.03 \\
\hline
\end{tabular}

Notes: *Statistically different when compared with **. The numbers represent the mean of three independent experiments.

Abbreviations: $\mathrm{HWH}$, hot water hyperthermia; $\mathrm{MFH}$, magnetic fluid hyperthermia; $\mathrm{SD}$, standard deviation; SE, standard error.

\section{Discussion}

In the present work, we have shown that the presence of extracellular copper at a concentration close to the $\mathrm{K}_{\mathrm{m}}$ value of hCTR1 reduces cDDP-induced cytotoxicity in Caco- 2 cells at cisplatin concentrations above $5 \mu \mathrm{M}$ (Figure 1) ${ }^{39}$ In order to determine whether the aforementioned concentration of extracellular copper is able to affect mild hyperthermicinduced cell toxicity, we treated Caco- 2 cells with cDDP at $41^{\circ} \mathrm{C}$ with either magnetic fluid hyperthermia or hot water hyperthermia, in the presence and absence of extracellular copper (Figure 2). We had previously reported differences in cell viability after combined treatment of cDDP and mild hot water hyperthermia or magnetic fluid hyperthermia at $41^{\circ} \mathrm{C} .{ }^{30}$ At the aforementioned temperature, differences in drug potentiation could be observed without compromising the fate of our entire cell sample.

Our results show that while copper serves a protective role in the context of long-term clonogenic survival when cells are treated concomitantly with hot water hyperthermia and cDDP, this protective role is not evident when magnetic fluid hyperthermia is used instead. No protective role in short-term cell viability was observed under our experimental conditions. These results suggest that the synergistic potentiation of cDDP with magnetic fluid hyperthermia differs from that of cDDP with hot water hyperthermia through a mechanism that appears to be independent of hCTR1-mediated drug influx. It is possible that the presence of extracellular copper is inhibiting the amount of cDDP that is being incorporated into cells exposed to hot water hyperthermia and control cells through a competitive binding interaction with hCTR1. In the case of cells treated with cDDP and magnetic fluid hyperthermia, the absence of a protective role by copper in the surviving fraction of cells suggests that this hyperthermic treatment might allow cDDP incorporation via an alternative route. Mild hyperthermia has been shown to increase cell membrane fluidity in different cell lines. ${ }^{41,42}$ In this study, we have shown that hyperthermia-induced cell membrane fluidity is one of the mechanisms responsible for cDDP potentiation in cancer cells and that the extent of drug potentiation and membrane fluidity varies greatly between the two forms of hyperthermia application, ie, magnetic fluid hyperthermia and hot water hyperthermia. cDDP potentiation using magnetic fluid hyperthermia is caused, at least in part, by an increase in cell membrane fluidity. Cells treated concomitantly with cDDP and magnetic fluid hyperthermia or hot water hyperthermia had higher platinum uptake than control cells. Cells treated at $41^{\circ} \mathrm{C}$ with magnetic fluid hyperthermia 

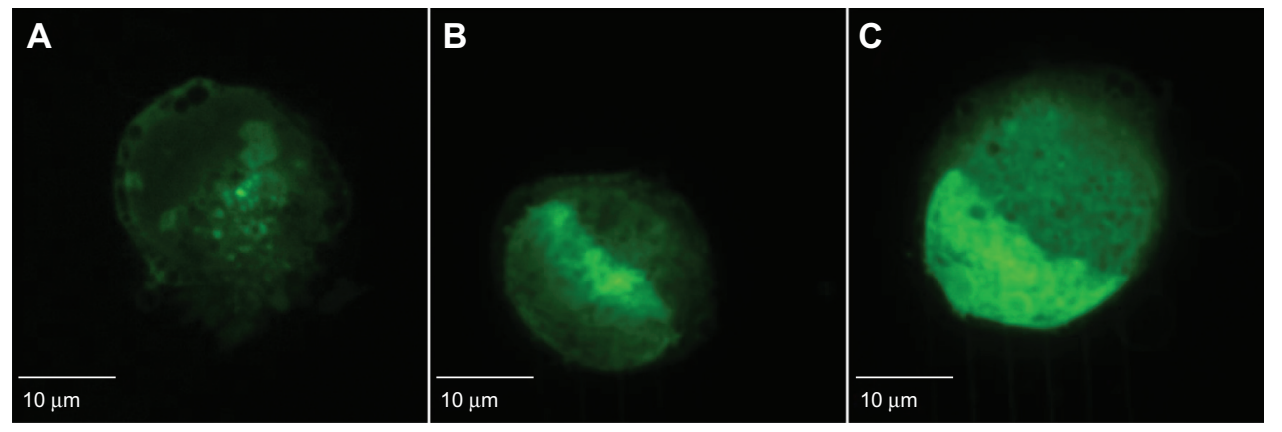

Figure 6 Acridine orange incorporation into cells treated with mild hyperthermia $\left(4 I^{\circ} \mathrm{C}\right)$. (A) Untreated cells. (B) Cells treated with water bath hyperthermia for 30 minutes. (C) Cells treated with magnetic fluid hyperthermia for 30 minutes (two independent experiments).

had a higher platinum uptake compared with cells treated with hot water hyperthermia at the same temperature. These results point to the possibility that magnetic fluid hyperthermia-induced cell membrane fluidity was more significant than that induced by hot water hyperthermia, allowing a higher uptake of cDDP to be transported passively across the cell membrane. In order to assess this possibility, we performed two independent experiments aimed at characterizing the membrane fluidity of cells exposed to magnetic fluid hyperthermia and hot water hyperthermia (Figure 4). Statistically significant differences in fluorescence anisotropy were observed between untreated cells and cells treated at $41^{\circ} \mathrm{C}$. Furthermore, a significant reduction in fluorescence anisotropy was observed in cells treated with magnetic fluid hyperthermia compared with hot water hyperthermia, suggesting that magnetic fluid hyperthermia increases cell membrane fluidity more dramatically. We also saw no significant differences in cDDP-induced membrane fluidity at the drug concentration used in this work. Finally, we quantified the amount of acridine orange which diffused into cells right after treatment with either magnetic fluid hyperthermia or hot water hyperthermia. Acridine orange is a weak base that can passively diffuse through the cell membrane. It fluoresces green when located in the cytoplasm and nucleus. ${ }^{43}$ Its fluorescence intensity is directly proportional to the amount of acridine orange that has entered into the cytoplasm and nucleus. Previous studies suggest that internalization of acridine orange into cells is mainly passive, so we hypothesized that its diffusion into cells would differ between treatments that affect the fluidity of the cell membrane. ${ }^{44}$ The fluorescence intensity of cells was analyzed quantitatively and qualitatively using flow cytometry and confocal microscopy, respectively. Statistically significant differences in fluorescence intensity were observed between cells treated with magnetic fluid hyperthermia and hot water hyperthermia (Table 1). Furthermore, qualitative differences in fluorescence intensity after exposure to acridine orange were observed for cells exposed to magnetic fluid hyperthermia and hot water hyperthermia.

\section{Conclusion}

To our knowledge, this work provides the first direct evidence of a mechanistic difference in the hyperthermic potentiation of a chemotherapeutic agent by hot water and magnetic fluid hyperthermia. Specifically, we have demonstrated that magnetic fluid hyperthermia enhances cDDP activity in cancer cells by enhancing passive uptake due to an increase in membrane fluidity. This mechanism was demonstrated by comparison of the reduction in cell viability and cDDP uptake in cells treated with magnetic fluid hyperthermia or hot water hyperthermia and cDDP with and without blocking active uptake through the CTR1 transporter. These studies demonstrated enhanced activity and uptake of cDDP in cells treated with magnetic fluid hyperthermia, regardless of the status of the CTR 1 transporter. Further experiments demonstrated increased membrane fluidity and passive uptake of the diffusing species in cells treated with magnetic fluid hyperthermia. Future studies aim at exploring downstream cell pathways that can provide further insight into the differences in cell outcomes between different forms of hyperthermic treatments. Although demonstrated in the context of cDDP, the demonstrated mechanism of enhanced passive uptake could find application in potentiation of other chemotherapeutics.

\section{Acknowledgments}

This work was supported by the US National Science Foundation UPRM CREST Program (HRD-0833112), Institute of Functional Nanomaterials (EPS-1002410), and NIH U54 (U54 CA 96300/U54 CA 96297). The authors 
are grateful to Lenibel Santiago and Daniel Rivera for their contribution to this work.

\section{Disclosure}

The authors report no conflicts of interest in this work.

\section{References}

1. Hahn GM, Li GC, Shiu E. Interaction of amphotericin B and 43 degrees hyperthermia. Cancer Res. 1977;37(3):761-764.

2. Hurwitz MD, Hansen JL, Prokopios-Davos S, et al. Hyperthermia combined with radiation for the treatment of locally advanced prostate cancer: long-term results from Dana-Farber Cancer Institute study 94-153. Cancer. 2011;117(3):510-516.

3. Vanakoski J, Seppala T. Heat exposure and drugs. A review of the effects of hyperthermia on pharmacokinetics. Clin Pharmacokinet. 1998;34(4):311-322.

4. van der Zee J. Heating the patient: a promising approach? Ann Oncol. 2002;13(8):1173-1184.

5. Rock E, Motta C, Vignon X, Kozak-Ribbens G. Fluidity state of lymphocyte plasma membrane in malignant hyperthermia susceptible pigs and humans. Acta Anaesthesiol Scand. 1993;37(5):488-492.

6. Dynlacht JR, Fox MH. The effect of 45 degrees $\mathrm{C}$ hyperthermia on the membrane fluidity of cells of several lines. Radiat Res. 1992; 130(1):55-60.

7. Kawamoto M, Fujii K, Kikuchi H, Morio M. Increased membrane fluidity of erythrocytes in a case with malignant hyperthermia. J Anesth. 1987;1(1):88-92.

8. Rao W, Deng ZS, Liu J. A review of hyperthermia combined with radiotherapy/chemotherapy on malignant tumors. Crit Rev Biomed Eng. 2010;38(1):101-116.

9. Kuo MT, Chen HH, Song IS, Savaraj N, Ishikawa T. The roles of copper transporters in cisplatin resistance. Cancer Metastasis Rev. 2007; 26(1):71-83.

10. Wang D, Lippard SJ. Cellular processing of platinum anticancer drugs. Nat Rev Drug Discov. 2005;4(4):307-320.

11. Safaei R, Howell SB. Copper transporters regulate the cellular pharmacology and sensitivity to Pt drugs. Crit Rev Oncol Hematol. 2005;53(1): 13-23.

12. Safaei R. Role of copper transporters in the uptake and efflux of platinum containing drugs. Cancer Lett. 2006;234(1):34-39.

13. Lee J, Pena MM, Nose Y, Thiele DJ. Biochemical characterization of the human copper transporter Ctr1. J Biol Chem. 2002;277(6): 4380-4387.

14. Ishida S, Lee J, Thiele DJ, Herskowitz I. Uptake of the anticancer drug cisplatin mediated by the copper transporter Ctr1 in yeast and mammals. Proc Natl Acad Sci U S A. 2002;99(22):14298-14302.

15. Ohashi K, Kajiya K, Inaba S, et al. Copper(II) protects yeast against the toxicity of cisplatin independently of the induction of metallothionein and the inhibition of platinum uptake. Biochem Biophys Res Commun. 2003;310(1):148-152.

16. Ishida S, McCormick F, Smith-McCune K, Hanahan D. Enhancing tumor-specific uptake of the anticancer drug cisplatin with a copper chelator. Cancer Cell. 2010;17(6):574-583.

17. Holzer AK, Katano K, Klomp LW, Howell SB. Cisplatin rapidly downregulates its own influx transporter hCTR1 in cultured human ovarian carcinoma cells. Clin Cancer Res. 2004;10(19):6744-6749.

18. Molloy SA, Kaplan JH. Copper-dependent recycling of hCTR1, the human high affinity copper transporter. J Biol Chem. 2009;284(43): 29704-29713.

19. Sinani D, Adle DJ, Kim H, Lee J. Distinct mechanisms for Ctr1-mediated copper and cisplatin transport. J Biol Chem. 2007;282(37): 26775-26785.

20. Blair BG, Larson CA, Safaei R, Howell SB. Copper transporter 2 regulates the cellular accumulation and cytotoxicity of cisplatin and carboplatin. Clin Cancer Res. 2009;15(13):4312-4321.
21. Blair BG, Larson CA, Adams PL, Abada PB, Safaei R, Howell SB. Regulation of copper transporter 2 expression by copper and cisplatin in human ovarian carcinoma cells. Mol Pharmacol. 2010;77(6): 912-921.

22. Jandial DD, Farshchi-Heydari S, Larson CA, Elliott GI, Wrasidlo WJ, Howell SB. Enhanced delivery of cisplatin to intraperitoneal ovarian carcinomas mediated by the effects of bortezomib on the human copper transporter 1. Clin Cancer Res. 2009;15(2):553-560.

23. Holzer AK, Varki NM, Le QT, Gibson MA, Naredi P, Howell SB. Expression of the human copper influx transporter 1 in normal and malignant human tissues. J Histochem Cytochem. 2006;54(9): 1041-1049.

24. Eisses JF, Chi Y, Kaplan JH. Stable plasma membrane levels of hCTR1 mediate cellular copper uptake. J Biol Chem. 2005;280(10): 9635-9639.

25. Hettinga JV, Lemstra W, De Vries EG, Konings AW, Kampinga HH. Sensitization to cisplatin action by step-down heating in cDDP-sensitive and -resistant cells. Int J Cancer. 1995;61(5):722-726.

26. Kumar CS, Mohammad F. Magnetic nanomaterials for hyperthermiabased therapy and controlled drug delivery. Adv Drug Deliv Rev. 2011;63(9):789-808.

27. Lee JH, Jang JT, Choi JS, et al. Exchange-coupled magnetic nanoparticles for efficient heat induction. Nat Nanotechnol. 2011;6(7):418-422.

28. Banerjee R, Katsenovich Y, Lagos L, McIintosh M, Zhang X, Li CZ. Nanomedicine: magnetic nanoparticles and their biomedical applications. Curr Med Chem. 2010;17(27):3120-3141.

29. Rodriguez-Luccioni HL, Latorre-Esteves M, Mendez-Vega J, et al. Enhanced reduction in cell viability by hyperthermia induced by magnetic nanoparticles. Int J Nanomedicine. 2011;6:373-380.

30. Lee JS, Rodriguez-Luccioni HL, Mendez J, et al. Hyperthermia induced by magnetic nanoparticles improves the effectiveness of the anticancer drug cis-diamminedichloroplatinum. J Nanosci Nanotechnol. 2011;11(5):4153-4157.

31. Howell SB, Safaei R, Larson CA, Sailor MJ. Copper transporters and the cellular pharmacology of the platinum-containing cancer drugs. Mol Pharmacol. 2010;77(6):887-894.

32. Franken NA, Rodermond HM, Stap J, Haveman J, van Bree C. Clonogenic assay of cells in vitro. Nat Protoc. 2006;1(5):2315-2319.

33. Ghezzi A, Aceto M, Cassino C, Gabano E, Osella D. Uptake of antitumor platinum(II)-complexes by cancer cells, assayed by inductively coupled plasma mass spectrometry (ICP-MS). J Inorg Biochem. 2004;98(1):73-78.

34. Gantet P, Hubac C, Brown SC. Flow Cytometric Fluorescence Anisotropy of Lipophilic Probes in Epidermal and Mesophyll Protoplasts from Water-Stressed Lupinus albus L. Plant Physiol. 1990;94(2): 729-737.

35. Gupta N, Lamborn K, Deen DF. A statistical approach for analyzing clonogenic survival data. Radiat Res. 1996;145(5):636-640.

36. Gonzales-Weimuller M, Zeisberger M, Krishnan KM. Size-dependant heating rates of iron oxide nanoparticles for magnetic fluid hyperthermia. J Magn Mag Mater. 2009;321(13):1947-1950.

37. Dennis CL, Jackson AJ, Borchers JA, et al. The influence of magnetic and physiological behaviour on the effectiveness of iron oxide nanoparticles for hyperthermia. J Phys D: Appl Phys. 2008;41(13):134020.

38. Dennis CL, Jackson AJ, Borchers JA, et al. The influence of collective behavior on the magnetic and heating properties of iron oxide nanoparticles. J Appl Phys. 2008;103(7):07A319.

39. Eisses JF, Kaplan JH. Molecular characterization of hCTR1, the human copper uptake protein. J Biol Chem. 2002;277(32):29162-29171.

40. Azenabor AA, Job G, Adedokun OO. Chlamydia pneumoniae infected macrophages exhibit enhanced plasma membrane fluidity and show increased adherence to endothelial cells. Mol Cell Biochem. 2005;269(1-2):69-84.

41. Balogh G, Horvath I, Nagy E, et al. The hyperfluidization of mammalian cell membranes acts as a signal to initiate the heat shock protein response. FEBS J. 2005;272(23):6077-6086. 
42. Moulin M, Carpentier S, Levade T, Arrigo AP. Potential roles of membrane fluidity and ceramide in hyperthermia and alcohol stimulation of TRAIL apoptosis. Apoptosis. 2007;12(9):1703-1720.

43. Paglin S, Hollister T, Delohery T, et al. A novel response of cancer cells to radiation involves autophagy and formation of acidic vesicles. Cancer Res. 2001;61(2):439-444.
44. Dechsupa N, Mankhetkorn S. P-Glycoprotein-Mediated Efflux and Drug Sequestration in Lysosomes Confer Advantages of K562 Multidrug Resistance Sublines to Survive Prolonged Exposure to Cytotoxic Agents. Am J Appl Sci. 2009;6(9):1637-1646.

International Journal of Nanomedicine

\section{Publish your work in this journal}

The International Journal of Nanomedicine is an international, peerreviewed journal focusing on the application of nanotechnology in diagnostics, therapeutics, and drug delivery systems throughout the biomedical field. This journal is indexed on PubMed Central,

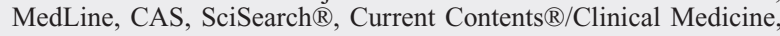

Journal Citation Reports/Science Edition, EMBase, Scopus and the Elsevier Bibliographic databases. The manuscript management system is completely online and includes a very quick and fair peer-review system, which is all easy to use. Visit http://www.dovepress.com/ testimonials.php to read real quotes from published authors.

Submit your manuscript here: http://www.dovepress.com/international-journal-of-nanomedicine-journal 